\title{
The Surface Structure of Gold
}

\section{THE ORIGIN OF ABNORMALITIES IN THE OUTER ATOMIC LAYERS}

\author{
P. J. Dobson \\ Physics Department, Imperial College, London
}

The anomalous nature of the first two or three atomic layers of a gold surface has an important effect in a number of technical fields, including catalysis and the bonding to semiconductors, and could be responsible for its resistance to oxidation. This paper reviews our present knowledge of the single crystal surfaces of gold and attempts to reconcile some conflicting ideas that have been put forward on the origin of the anomalous structure observed on the cube face.

Gold, because of its relative inertness and resistance to chemical attack, has been traditionally a popular choice by research workers wishing to examine the behaviour of a metallic surface unaffected by oxides or corrosion products. However, the modern surface research worker with extreme criteria for cleanliness on an atomic scale must question all assumptions regarding the composition of any surface. In studies of mechanical, electrical or chemical properties, the main questions to be answered about any clean surface are: "How clean is it ?"; "What is the atomic structure and how does the surface deviate from the bulk material ?". The gold $\{100\}$ surface in particular has produced a puzzle that, at present, is not completely resolved.

Surface physics and chemistry received a boost in the 1960 's due to the ready availability of commercial ultra-high vacuum apparatus. In particular, the availability of equipment for low energy electron diffraction (LEED) $(1,2,3)$ and for reflection high energy electron diffraction (RHEED) (4) permitted

Fig. 1 A typical $5 \times 1$ LEED pattern from a $\{100\}$ gold surface. This pattem may be explained by the presence of a hexagonal overlayer on a cubic structure determination of the atomic structure and spacing of the outermost layer of surfaces. LEED utilises electrons of energy in the range 30 to $1000 \mathrm{ev}$, at which energies the atomic scattering factors are large. Consequently the penetration of low energy electrons in a solid is very low (typically a few atomic spacings) and the diffracted beams give structural information about the outermost atomic layers. The most commonly used LEED apparatus is the direct display type in which the backscattered electron diffraction pattern is observed on a fluorescent screen. The angles between the diffracted beams can be determined from photographs of the diffraction pattern and this gives directly the spacing of atoms in the plane of the surface. In principle, the spacing of atoms normal to the surface can be obtained from measurements of the intensities of diffracted beams as a function of primary beam energy. However, a complete dynamical theory that takes into account multiple scattering of the diffracted beams is needed before such information can be extracted. Such a theory should be available within the next few years.

RHEED utilises electron beams of energy $20 \mathrm{keV}$ to $100 \mathrm{keV}$ incident at grazing incidence on surfaces. Even though penetration of high energy electrons is relatively high, the use of grazing incidence (typically of the order of one degree) means that only the outermost two or three atomic layers contribute to the diffraction pattern. Results from RHEED are generally complementary to those from LEED.

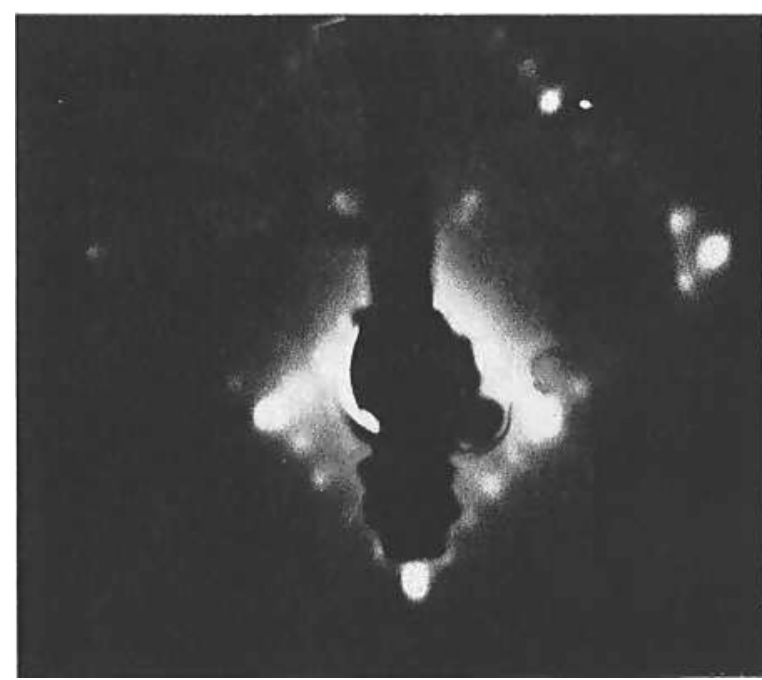


Auger spectroscopy $(5,6)$ which may be conveniently incorporated into LEED vacuum chambers was also developed in recent years. This technique permits identification of atoms in the outermost two or three atomic layers, and in combination with LEED forms a very powerful analytical tool.

Up to 1966 LEED studies had shown that the surface of most metals was "normal", i.e., the spacing and arrangement of atoms in the surface was the same as expected from bulk crystallographic data. However, in a systematic study of the gold $\{111\}\{110\}$ and $\{100\}$ surfaces, Fedak and Gjostein $(7,8)$ observed anomalous structures for the latter orientations. Since then, much attention has been fucused on the $\{100\}$ surface. The LEED patterns observed by Fedak and Gjostein and subsequently others are summarised in the table. Most of these exhibited $1 / 5$ th order diffracted beams as shown in Figs. 1 and 2 . These are known as $5 \times 1$ patterns after the terminology of surface crystallography (9). This implies that there is a long range coincidence lattice of spacing five times the spacing expected from a bulk $\{100\}$ plane. Later work (10) showed that LEED patterns were not always simply $5 \times 1$ but more likely $5 \times 20$, i.e., splitting of beams was observed under higher resolution, particularly at low electron beam energies (less than $50 \mathrm{eV}$ ). This splitting was $1 / 20$ th of the "normal" reciprocal lattice vector. Fig. 2 shows a schematic diagram of such a pattern (11). The table summarises the results of studies of the $\{100\}$ gold surface. It should be noted that the gold $\{110\}$ surface exhibited $2 \times 1$ patterns (8). Platinum (21) and iridium (22) $\{100\}$ surfaces also exhibit $5 \times 1$ or $5 \times 20$ patterns. The main question asked by surface research workers is whether these $5 \times 1$ or $5 \times 20$ LEED patterns are characteristic of an atomically clean gold $\{100\}$ surface or are due to the presence of an impurity structure on the surface. The answer to this question should be compatible with the fact that the other noble metals, silver and copper, do not exhibit such LEED patterns, i.e., they appear to be "normal".

\section{Summary of Investigations on the $\{100\}$ Gold Surface}

\begin{tabular}{|c|c|c|c|c|c|}
\hline & Technique & Structure & Sample & Preparation & Model \\
\hline $\begin{array}{l}\text { Fedak and Gjostein } \\
(7,8,10)\end{array}$ & LEED & $\begin{array}{ll}5 \times 1 \rightarrow 1 \times 1 \\
5 \times 20 \quad 800^{\circ} \mathrm{C} \\
& \text { or ion bomb }\end{array}$ & $\begin{array}{l}\text { Bulk } \\
\text { crystal }\end{array}$ & $\begin{array}{l}\text { lon } \\
\text { bombardment } \\
\text { + anneal }\end{array}$ & $\begin{array}{l}\text { Impurity } \\
\text { reconstructed }\end{array}$ \\
\hline Fedak et al (12) & LEED & $\underset{5 \times 20 \rightarrow 1 \times 1}{\mathrm{Cl}_{2}}$ & $\begin{array}{l}\text { Bulk } \\
\text { crystal }\end{array}$ & $\begin{array}{l}\text { lon } \\
\text { bombardment } \\
\text { +anneal }\end{array}$ & $\begin{array}{l}\text { Impurity } \\
\text { reconstructed }\end{array}$ \\
\hline Mattera et al (13) & LEED & $\begin{array}{l}5 \times 1 \\
6 \times 6\end{array}$ & $\begin{array}{l}\text { Bulk } \\
\text { crystal }\end{array}$ & $\begin{array}{l}\text { Ion } \\
\text { bombardment } \\
\text { +anneal }\end{array}$ & $\begin{array}{l}\text { Surface } \\
\text { vacancy }\end{array}$ \\
\hline $\begin{array}{l}\text { Palmberg and Rhodin } \\
\qquad(14,15)\end{array}$ & LEED & $\begin{array}{l}5 \times 1 \\
5 \times 20\end{array}$ & $\begin{array}{l}\text { Thin } \\
\text { epitaxial } \\
\text { film }\end{array}$ & $\begin{array}{l}\text { Epitaxial } \\
\text { growth } \\
\text { in u.h.v. }\end{array}$ & $\begin{array}{l}\text { Clean } \\
\text { reconstructed }\end{array}$ \\
\hline Bauer et al (16) & RHEED & $5 \times 1$ & $\begin{array}{l}\text { Thin } \\
\text { epitaxial } \\
\text { film }\end{array}$ & $\begin{array}{l}\text { Epitaxial } \\
\text { growth } \\
\text { in u.h.v. }\end{array}$ & $\begin{array}{l}\text { Impurity } \\
\text { reconstructed }\end{array}$ \\
\hline Bauer (17) & LEED & $\begin{array}{l}5 \times 1 \\
5 \times 20\end{array}$ & $\begin{array}{l}\text { Gold } \\
\text { crystal } \\
+\mathrm{Na}\end{array}$ & $\begin{array}{l}\text { Epitaxial } \\
\text { growth } \\
\text { of } \mathrm{Na}\end{array}$ & $\begin{array}{l}\text { Impurity } \\
\text { reconstructed }\end{array}$ \\
\hline $\begin{array}{l}\text { Dennis and Dobson } \\
\text { (18) }\end{array}$ & $\begin{array}{l}\text { LEED } \\
\text { (RHEED) }\end{array}$ & $\begin{array}{l}5 \times 1 \\
5 \times 20\end{array}$ & $\begin{array}{l}\text { Thin } \\
\text { epitaxial } \\
\text { film }\end{array}$ & $\begin{array}{l}\text { Epitaxial } \\
\text { growth } \\
\text { in u.h.v. }\end{array}$ & $\begin{array}{l}\text { Surface } \\
\text { twinning }\end{array}$ \\
\hline $\begin{array}{l}\text { Gronlund and Hojlund- } \\
\text { Nielsen (19) }\end{array}$ & RHEED & $\begin{array}{l}\text { Hexagonal (similar to } \\
\text { overlayer } 5 \times 20)\end{array}$ & $\begin{array}{l}\text { Bulk } \\
\text { crystal }\end{array}$ & $\begin{array}{l}\text { Heating to } \\
200^{\circ} \mathrm{C} \text { at } \\
10^{-8} \text { torr }\end{array}$ & \\
\hline $\begin{array}{l}\text { Rhead (11) } \\
\text { Biberian and Rhead } \\
\quad(20)\end{array}$ & LEED & $\begin{array}{l}+ \text { trace } S, P b \\
5 \times 20 \rightarrow 1 \times 1\end{array}$ & $\begin{array}{l}\text { Bulk } \\
\text { crystal }\end{array}$ & $\begin{array}{l}\text { Ion } \\
\text { bombardment } \\
\text { + anneal }\end{array}$ & $\begin{array}{l}\text { Clean } \\
\text { reconstructed }\end{array}$ \\
\hline
\end{tabular}


Fig. 2 A schematic diagram of LEED patterns

(a) From an unreconstructed $\{100\}$ face centred cubic surface, i.e. a $1 \times 1$ pattern

(b) A $5 \times 1$ pattern, which implies a five times repeat distance of the basic lattice

(c) A $5 \times 20$ pattern, implying a five times repeat distance in one direction and a twenty times repeat distance at right angles.

(After Rhead (11))

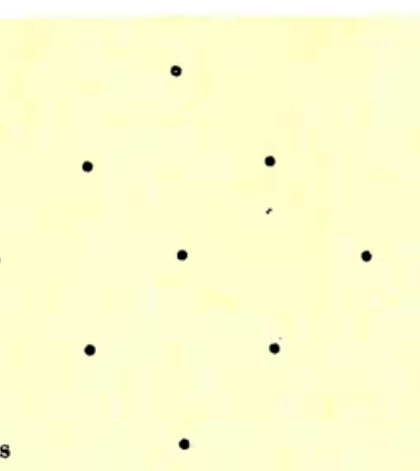

(a)

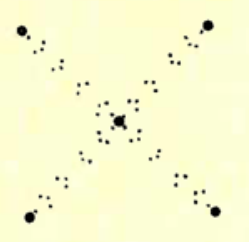

(c)

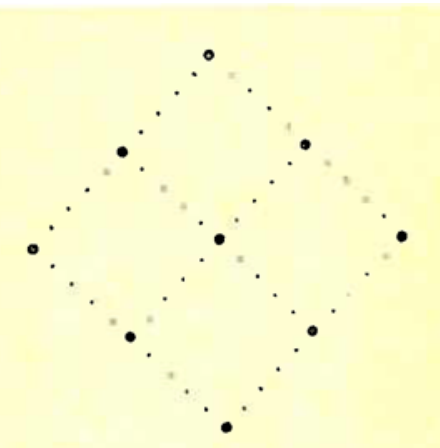

(b)

There are several points against this model. There

\section{Models of the $\{100\}$ Gold Surface}

It is convenient to divide the models into three main categories, namely the clean reconstructed surface model; impurity stabilised reconstruction; surface defect model. For the first two models it is generally agreed that LEED and RHEED results are compatible with the model of a hexagonal overlayer of atoms with interatomic spacing 5 per cent less than bulk gold, superimposed on unreconstructed $\{100\}$ gold planes $(14,15,10)$. This is shown in Fig. 3 . The $1 / 5$ th, $1 / 20$ th order features are then a result of multiple diffraction between "overlayer" and "substrate" beams (15). This model has been shown (11) to account for splitting of fractional order beams.

\section{(a) Clean Reconstructed Surface Model}

The basis of this model is that the constrained hexagonal layer referred to above consists only of gold atoms. This conjecture was supported by Auger spectroscopic evidence which, it was claimed, showed that the surface impurity concentration is at the most, a few parts in $10^{3}$. This statement can only be justified if the Auger transitions due to an impurity do not coincide with gold Auger transitions and the sensitivity of the technique is sufficient to detect particular contaminants. The justification of the model was based upon considerations of minimisation of surface energy and enhancement of surface valence by contraction of interatomic spacing. From considerations of the electronic configuration, molecular dissociation energy and internuclear spacing in molecules and other reasons, Palmberg and Rhodin $(14,15)$ concluded that gold was more likely than copper and silver to exhibit spacing changes and hence reconstruction at the surface. must exist a fine balance of surface and interfacial free energies if such a hexagonal layer is to be stable for a pure system. Mass spectrometric observations (12) suggest that alkali metal impurities are present at the surface and, in particular, the effect of chlorine adsorption (12) which irreversibly transforms the $5 \times 1$ to $1 \times 1$ surface is difficult to explain by any clean surface hypothesis. Finally, despite the convincing justification for occurrence of the anomalous structure on gold $\{100\}$ surfaces offered by Palmberg and Rhodin, no satisfactory account has been given for reconstruction of the $\{110\}$ surface, or of similarities with platinum and iridium $\{100\}$ surfaces.

\section{(b) Impurity Stabilised Reconstruction}

Fedak and Gjostein (10) suggested that it was unlikely from an energetic point of view that a hexagonal layer of gold atoms should be stable on a $\{100\}$ surface. Mass spectrometric results (12) suggest alkali impurities and other studies have shown that sodium structures, in particular, on gold yield $5 \times 1$ and $5 \times 20$ patterns $(16,17)$. The various reports of transformation to $1 \times 1$ following adsorption of either chlorine (12), lead or sulphur (20) are more compatible with this model than a "clean surface" model, the adsorbate possibly forming small nuclei of a compound (e.g. $\mathrm{NaCl}$ ), undetected by LEED. The reversible change from $5 \times 1$ to $1 \times 1$ at high temperatures $(8,10)$ is also compatible with impurity desorption above $800^{\circ} \mathrm{C}$, but re-appearance of the impurity by diffusion from the bulk crystal as the temperature is lowered.

Among the points against this model is the fact that different preparation and cleaning procedures 


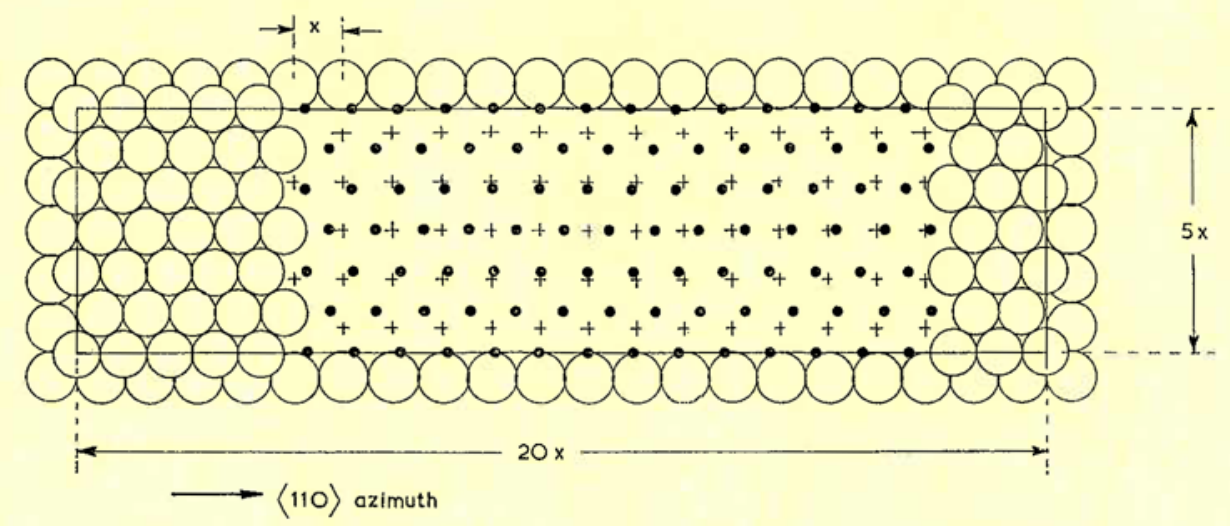

Fig. 3 The $5 \times 20$ "cell" of the reconstructed $\{100\}$ gold surface. Atoms have been omitted for clarity

+ Atom positions in bulk position in second layer

- Atom positions in outermost layer

$x=a_{0} / \sqrt{2}$ where $a_{0}=$ bulk lattice spacing

have resulted in similar $5 \times 1$ and $5 \times 20$ features, as will be seen from the table. It would at first sight seem unlikely that a particular impurity was always present. Also, there is the fact that Auger spectroscopy (15) failed to reveal a contaminant. However, of the likely impurities, sodium has $\mathrm{K}$ shell Auger transitions at greater than $900 \mathrm{eV}$ and a $\mathrm{L}_{1} \mathrm{~L}_{23} \mathrm{~V}$ transition at $\sim 17 \mathrm{eV}$, both outside of the range covered in early work. Potassium has a strong Auger transition at $\sim 252 \mathrm{eV}$, which almost coincides with a gold Auger transition at $\sim 256 \mathrm{eV}$. Fedak et al. (12) did observe changes in the Auger spectrum after chlorine adsorption. Therefore, it would seem necessary to employ other techniques such as X-ray photoelectron spectroscopy (23), secondary ion mass spectroscopy (24) or ion reflection spectroscopy (25) to detect any possible impurities.

If, as seems likely, the level of impurity is low, the rather drastic re-arrangement of the surface is surprising unless a well-defined compound is formed. If, as has been suggested (17), alkali plus noble metal compounds are responsible, more data are required regarding the structure and chemistry of these compounds, particularly in order to explain the non-reconstruction of copper and silver surfaces, and the reconstruction of the $\{110\}$ gold surface.

\section{(c) Surface Defect Models}

Mattera et al. (13) suggested that several f.c.c. metal surfaces exhibited reconstruction due to ordered arrays of vacancies which result from ion bombardment cleaning procedures. Some of the structures observed have not been seen by other workers, e.g. $6 \times 6\{100\}$ gold. This model seems difficult to justify on energetic grounds and does not explain adsorption or thermal transformations.

Dennis and Dobson (18), on the basis of observation of twinning by RHEED and electron microscopy in $\{100\}$ gold films suggested that twins in the surface region may be responsible for apparent reconstruction. Twinning in a f.c.c. lattice would expose $\{221\}$ planes parallel to the surface $\{100\}$. The $\{221\}$ plane is an open packed structure and if atom positions from successive layers are projected on to the surface, a pseudohexagonal structure results that is almost identical with that proposed for models $(a)$ and $(b)$. The low stacking fault and twin boundary energies for gold (26) are points in favour of this model, in that twins are easily formed. However, this also underlines a weakness, in that silver with comparable twin boundary energy (26) does not show reconstruction and platinum with very much higher twin boundary energy (26) does show reconstruction. Other points against this model have been published $(27,28)$, the difficulty of explaining adsorption effects being the principal reason for doubting the model.

\section{Conclusions}

The situation is still not completely resolved, although available evidence appears to be in favour of the impurity reconstruction model. It remains to be seen whether this model will explain similar observations for platinum $(21,29)$ and iridium (22) and the reconstruction of gold $\{110\}$. In addition to using other detection techniques, it would appear to be worth while to re-examine LEED data, particularly at low $(<50 \mathrm{eV})$ energies, when beam 
splitting is pronounced. Subtle differences exist between published LEED patterns, and it was observed (10) that beam splitting had some beam energy dependence.

Finally, it should be mentioned that careful X-ray measurements (30) have indicated an outward relaxation of the interplanar spacings of surface layers of $\sim 4$ per cent for gold $\{111\}$. These measurements were performed on air contaminated surfaces, and confirmation of such an effect must await LEED or RHEED data (and adequate theory) from surfaces prepared in ultra high vacuum. There is obviously a great deal of basic research yet to be performed on "clean" gold surfaces.

\section{References}

1 E. Bauer, "Techniques of Metals Research", Vol. 2, Ch. 16, Ed. Bunshah, (1969) Wiley

2 M. Prutton, Met. Rev., 1971, 16, 57

3. P. J. Estrup and E. G. McRae, Surface Sci., 1971, 25,1

4 E. Bauer, "Techniques of Metals Research", Vol. 2, Ch. 15, Ed. Bunshah, (1969) Wiley

5 C. C. Chang, Surface Sci., 1971, 25, 53

6 P. W. Palmberg, "Electron Spectroscopy", North Holland, Ed. Shirley, (1972), p. 835

7 D. G. Fedak and N. A. Gjostein, Phys. Rev. Lett., 1966, 16, 171

8 D. G. Fedak and N. A. Gjostein, Acta Met., 1967, 15, 827

9 E. A. Wood, F. Appl. Phys., 1964, 35, 1306
10 D. G. Fedak and N. A. Gjostein, Surface Sci., 1967, 8, 77

11 G. E. Rhead, F. Phys. F. Metal Phys., 1973, 3, L53

12 D. G. Fedak, J. V. Florio, W. D. Robertson, "The Structure and Chemistry of Solid Surfaces", Ed. G. A. Somorjai (1969), Wiley, p. 74-1

13 A. M. Mattera, R. M. Goodman and G. A. Somorjai, Surface Sci., 1967, 7, 26

14 P. W. Pal mberg and T. N. Rhodin, Phys. Rev., 1967, 161,586

15 P. W. Palmberg and T. N. Rhodin, 7. Chem. Phys., $1968,49,134$

16 E. Bauer, A. K. Green and K. M. Kunz, Appl. Phys. Lett., 1966, 8, 248

17 E. Bauer, "Structure et Propriétés des Surfaces des Solides", Paris (1969), p. 111

18 P. N. J. Dennis and P. J. Dobson, Surface Sci, 1972, 43, 3919

19 F. Grønlund and P. E. Højlund-Nielsen, f. Appl. Phys, 1972, 43, 3919

20 J. P. Biberian and G. E. Rhead, F. Phys. F. Metal Phys., 1973, 3, 675

21 S. Hagstrom, H. B. Lyon and G. A. Somorjai, Phys. Rev. Lett., 1965, 15, 491

22 J. T. Grant, Surface Sci., 1969, 18, 228

23 W. A. Fraser, J. V. Florio, W. N. Delgass and W. D. Robertson, Surface Sci., 1973, 36, 661

24 H. H. Brongersma and P. M. Mul, Surface Sci., 1973, 35, 393

25 A. Benninghoven, Surface Sci., 1973, 35, 427

26 L. E. Murr, Thin Solid Films, 1969, 4, 389 and Scripta Met., 1972, 6, 203

27 P. E. Højlund-Nielsen, Surface Sci., 1973, 36, 778

28 R. W. Joyner, submitted to Surface Sci.

29 A. E. Morgan and G. A. Somorjai, Surface Sci., 1968, 12, 405

30. R. W. Vook, S. Ouyang and M. A. Otooni, Surface Sci, $1972,29,277$

\section{Ordering in Gold-Copper Alloys}

\section{A STUDY BY THERMOPOWER MEASUREMENT}

It is only comparatively recently that the parameters upon which depends the absolute thermopower of a metal have been fully understood and it is for this reason that thermopower measurement has not hitherto been extensively utilised as a metallurgical tool. R. D. Barnard and A. J. M. Chivers of the University of Salford now suggest, however, that in certain circumstances the measurement of thermopower can provide a more sensitive alternative to the ubiquitous resistivity method for studying phase transitions and ordering processes in metals and alloys, and have applied it specifically to a study of the ordering kinetics of $\mathrm{CuAu}$ and $\mathrm{Au}_{3} \mathrm{Cu}$ (Metal Sci. F., 1973, 7, (July), 147-152). These are apt choices inasmuch as CuAu possesses two ordered phases both of which have resistivities lower than that of the disordered phase, while $\mathrm{Au}_{3} \mathrm{Cu}$ is anomalous in that it has a slightly higher resistivity in the ordered state. It is in this sort of situation that the resistivity method of studying phase changes has such obvious limitation.

The total thermoelectric power of metals and alloys is usually dominated by the diffusion component, $\mathrm{S}_{\mathrm{D}}$, which is a bulk property of any metal and whose value is of prime interest in this context for reasons which will become apparent.

Measurements were made using a simple thermocouple arrangement whereby the sample material and a reference metal were subjected to a temperature gradient. The Seebeck e.m.f., $\varepsilon$, thus produced is related to the absolute thermopower by the equation $d \varepsilon / d \mathrm{~T}=\mathrm{S}_{\mathrm{D} \text { (sample) }}-\mathrm{S}_{\mathrm{D} \text { (ref) }}$. It is clear, therefore, that provided $S_{D}($ (re) $)$ is a monotonic function of temperature, then changes in $\varepsilon$ can give a direct insight of the structural changes taking place in the sample. It is obviously desirable that the sample be kept in a virtually isothermal environment, - but to generate a measurable e.m.f. of even a few microvolts a small temperature gradient must be established.

With this in mind apparatus was constructed which permitted thermal e.m.f. measurement while enabling the temperature of the sample to be controlled, especially with respect to means of reducing the sample temperature to a stable level below the transition temperature as quickly as possible.

Samples were made up in the form of wire. With $\mathrm{Au}_{3} \mathrm{Cu}$ a conventional drawing process was employed but with $\mathrm{CuAu}$ it was necessary to cast the wire in a fine quartz tube.

Results obtained by this method are very encouraging, particularly for $\mathrm{Au}_{3} \mathrm{Cu}$ for which evidence came to light for the occurrence of short range ordering at temperatures considerably higher than those previously reported, as well as the existence of fine structure in the ordering curve. $\quad$ A. D. M. K. 